\title{
FREQUENCY OF NATURALLY OCCURRING MAXILLARY MIDLINE DIASTEMA (MMD) AND ITS ASSOCIATION WITH ENLARGED LABIAL FRENULUM IN STUDENTS OF PUBLIC MEDICAL COLLEGE MARDAN, PAKISTAN
}

\author{
Wajiha Qamar ${ }^{1}$, Sidra Qadir ${ }^{1}$, Hazrat Bilal ${ }^{1}$, Ahmad $^{1}$ \\ 1. Bacha Khan Medical College, Mardan
}

\section{ABSTRACT:}

\section{OBJECTIVE:}

The study was conducted to determine the prevalence of naturally occurring maxillary midline diastema (MMD) in students of public sector medical college in Mardan, Pakistan and its association with enlarged labial frenulum.

\section{METHODOLOGY:}

The cross-sectional study was conducted in Mardan where students were assessed to determine MMD. Sample size was 150 (males 76\%, $n=114$; females 24\%, $n=36$ ). Ethical consideration was followed, and data was analyzed using SPSS version 17 for descriptive statistics.

\section{RESULTS:}

Only 20\% (n=30) male students were having MMD while out of these only $20 \%(n=6)$ were having enlarged labial frenulum. No MMD was found in female students

\section{CONCLUSION:}

The maxillary midline diastema is more pronounced in male students and the authors decline the observation based on their findings that major contributing factor in MMD is because of enlarged labial frenulum.

KEYWORDS: Maxillary Midline Diastema, Labial Frenulum, Mardan

\section{INTRODUCTION:}

Maxillary midline diastema is the space between anterior teeth which exceeds $0.5 \mathrm{~mm}$ size. In some

\begin{tabular}{|c|c|}
\hline $\begin{array}{c}\text { Correspondence } \\
\text { Wajiha Qamar }\end{array}$ & $\begin{array}{c}\text { cultures, and } \\
\text { ethnic groups, } \\
\text { Department of Oral Biology } \\
\text { Bacha Khan Medical College, Mardan } \\
\text { Email: wajihaqamar.ob@gmail.com } \\
\text { Phone: 0332-7594914 }\end{array}$ \\
$\begin{array}{c}\text { as a symbol of } \\
\text { beauty while }\end{array}$ \\
\hline https://doi.org/10.37762/jgmds.5-1.11 &
\end{tabular}
consider it not appealing. Dental appearance of a person is considered an important feature in determining the attractiveness of a person's face $^{1,2}$. The key features in dental appearance are shape, size, position and alignment of teeth. Variation from normal pattern often has a negative impact on person's appearance. A diastema is space between anterior teeth; maxillary midline diastema is usually seen during eruption of teeth and closes with eruption of canine. The diastema could also be associated with dental malformation e.g. congenitally missing teeth, supernumerary teeth, peg shaped lateral incisor, palatially displaced canine or high frenal attachment ${ }^{3}$. Diastema is perceived differently in different cultures, age group and racial background; to some it's considered as a symbol of beauty while to other it's aesthetically displeasing ${ }^{4}$. It is common in maxillary teeth and therefore common terminology of maxillary midline diastema (MMD) is used $^{5}$. The MMD is classified if the space between the central incisors is more than 0.5 $\mathrm{mm}^{5}$. Study shows that MMD was more prevalent in African descent then Caucasians and Asians 
while it was moderately prevalent in Middle East ${ }^{5,6}$. Also the same study reports that some African countries associate diastema not only as symbol of beauty but also an indication of fertility, similarly in France they refer it to as "dents dubonheur" means lucky teeth ${ }^{6}$. Very limited studies have been conducted to determine the prevalence of diastema in Asia especially in Pakistan. The study was conducted with an objective to determine the MMD prevalence among medical and dental students of a public medical college in district Mardan, Pakistan. The study also explores the association of MMD with enlarged frenulum.

\section{METHODOLOGY:}

This cross-sectional study was conducted in a public sector medical college in district Mardan, Pakistan from January to April 2018. The study was approved by the ethical committee of the respective medical college. Study subjects were students enrolled for bachelor's in dental surgery (BDS) and Bachelor of Medicine, Bachelor of Surgery (MBBS). Response rate was $52.1 \%$. Sample size was $150(76 \%, n=114)$ of our study population was males while $(24 \%, n=36)$ were females. The students included in the study were explained the study objective and verbal consent was taken. The students were informed that data will remain confidential and their information will be presented only as a group data. Dental and medical history was taken of all study subjects followed by assessment by a team of oral biologists. Panoramic view and periapical were used wherever applicable. Data was cross checked, double coded to make sure it was free of error. Analysis was done using SPSS version 17. Descriptive statistics were performed.

\section{RESULTS:}

Our study found that $20 \%(n=30)$ male students were having MMD. Interestingly MMD was not seen in any of the female students enrolled in the study. Table 1 shows the tabular description. As shown in Table 1, out of these 30 male students presenting with MMD, $20 \%(n=6)$ students were having enlarged labial frenulum. The tabular description could be seen in Table 2. We also found in our study that only $5.3 \%(n=8)$ subjects were having generalized spacing in maxillary teeth as illustrated in Table 3.

Table 1: Presence of Maxillary Midline Diastema

\begin{tabular}{|c|c|c|c|}
\hline Gender & Yes & No & Total \\
\hline Male & 30 & 84 & 114 \\
\hline Female & 0 & 36 & 36 \\
\hline Total & 30 & 120 & 150 \\
\hline
\end{tabular}

Table 2: Enlarged Frenulum of Upper Lip

\begin{tabular}{|c|c|c|c|}
\hline Gender & Yes & No & Total \\
\hline Male & 6 & 108 & 114 \\
\hline Female & 0 & 36 & 36 \\
\hline Total & 6 & 144 & 150 \\
\hline
\end{tabular}


Table 3: Generalized Spacing in Maxillary Teeth

\begin{tabular}{|c|c|c|c|}
\hline Gender & Yes & No & Total \\
\hline Male & 8 & 106 & 114 \\
\hline Female & 0 & 36 & 36 \\
\hline Total & 8 & 142 & 150 \\
\hline
\end{tabular}

\section{DISCUSSION:}

Disparities have been observed in population and ethnic groups with regards to esthetic perception of MMD. Study conducted in Owerri, Nigeria found the prevalence of $28.4 \%$ naturally occurring MMD and is supported by studies conducted in South Western Nigeria and Tanzania where prevalence of MMD reported was $21 \%$ and $26 \%$ respectively $5,7,8$. The findings of the study are comparable to our study where prevalence was reported $20 \%$ in medical and dental students. Studies found that the trait was more common in females than males ${ }^{5,7,9,10}$ which is contrary to our findings where the trait was seen only in males. This could be attributed to the fact that in our study $76 \%$ of the sample size was representing male students. Several factors have been reported leading to diastema which predominantly includes superior labial frenulum, mismatched teeth, tongue thrust and abnormal jaw bone. The possible influence of superior labial frenulum is of immense importance to clinicians in playing a vital role in $\mathrm{MMD}^{3}$. We found based on our study that the subject exhibiting enlarged labial frenulum were only $20 \%$. Comparable study on these parameters were not found.

\section{CONCLUSION:}

Within the limitation of the study, the authors conclude that the maxillary midline diastema is more pronounced in male students and the authors decline the observation based on their findings that major contributing factor in MMD is because of enlarged labial frenulum. Limited research has been conducted in this area especially in Pakistan and Asia. The authors also suggest conducting further studies in this area.

\section{REFERENCES:}

1. Tin-Oo MM, Saddki N, Hassan N. Factors influencing patient satisfaction with dental appearance and treatments they desire to improve aesthetics. BMC Oral Health. 2011;11(1):6.

2. Qualtrough AJ, Burke FJ. A look at dental esthetics. Quintessence Int. 1994;25(1):7-14.

3. Huang WJ, Creath CJ. The midline diastema: a review of its etiology and treatment. Pediatr Dentistry. 1995;17(3):171-79.

4. Kumar A, Shetty RM, Dixit U, Mallikarjun K, Kohli A. Orthodontic management of midline diastema in mixed dentition. Int $\mathrm{J}$ Clin Pediatr Dentistry. 2011;4(1):59-63.

5. Umanah A, Omogbai AA, Osagbemiro B. Prevalence of artificially created maxillary midline diastema and its complications in a selected Nigerian population. Afr Health Sci. 2015;15(1):226-32.

6. Syed S, Al Shahrani I, Togoo R, Alshahrani A, Alshahrani A, Alshehri D. Esthetic perception of maxillary midline diastema among female students at King Khalid University. Gulf Med J. 2017;6(10):49-54.

7. Omotosho GO, Kadir E. Midline diastema amongst South-Western Nigeria. Internet J Dent Sci. 2010;8(2). 
8. Athumani AP, Mugonzibwa EA. Perception on diastema medialle (mwanya) among dental patients attending Muhimbili National Hospital. Tanzania Dent J. 2006;12(2):50-7.

9. Abu-Hussein M, Watted N. Maxillary midline diastema-aetiology and orthodontic treatment-clinical review. J Dent Med Sci. 2016;15:116-30.
10. Kaimenyi JT. Occurrence of midline diastema and frenum attachments amongst school children in Nairobi, Kenya. Indian J Dent Res. 1998;9(2):67-71.

LICENSE: JGMDS publishes its articles under a Creative Commons Attribution Non-Commercial Share-Alike license (CC-BY-NC-SA 4.0). COPYRIGHTS: Authors retain the rights without any restrictions to freely download, print, share and disseminate the article for any lawful purpose. It includes scholarly networks such as Research Gate, Google Scholar, LinkedIn, Academia.edu, Twitter, and other academic or professional networking sites. 